\title{
LA CONSTRUCCIÓN DE LA IDENTIDAD FEMENINA EN LA LITERATURA CLÁSICA ESPAÑOLA DEL S. XV AL S. XVII
}

\author{
Begoña Souviron \\ (Universidad de Málaga) \\ bsouviron@uma.es
}

\begin{abstract}
RESUMEN: Las mujeres levantan su voz en la ficción literaria. Son mujeres desplazadas, a menudo disfrazadas o con hábitos, las que asumen la defensa de sus libertades en el amor o reivindican su derecho a la educación. Muchas veces las mujeres amenazan el orden impuesto y son perseguidas, violadas o vendidas por sus propios padres o tutores. Otras ingresan en el convento y hacen votos para construir desde dentro su identidad. Todas ellas encuentran un espacio de realización personal y representación en la literatura. En nuestro trabajo dedicamos especial atención al testimonio de Aldonza, la protagonista de la obra de Francisco Delicado, La lozana andaluza, y a otras protagonistas de la novela del Siglo de Oro, así como a las voces de Teresa de Cartagena, Teresa de Jesús y sor Juana Inés de la cruz.

PALABRAS ClaVE: Voces femeninas, Mujer en la literatura, Defensa del derecho a la educación femenina.
\end{abstract}

\section{CONSTRUCTION OF FEMALE IDENTITY IN CLASSICAL LITERATURE FROM XV TO XVII CENTURY}

ABSTRACT: Women raise their voices in literary fiction. They are displaced women, often in disguise, who assume the defense of their freedoms in love or claim their right to education. Many times women threaten the imposed order and are persecuted, raped or sold by their own parents or guardians. Others they enter the convent and vow to build their identity from within. All of them find a space for personal fulfillment and representation in literature. In our work we pay special attention to the testimony of Aldonza, the protagonist of the work of Francisco Delicado, La Lozana Andaluza, and other protagonists of classic novels. We pay attention also to Teresa de Cartagena, Teresa de Jesús and Sor Juana Inés de la Cruz.

KEYWORDS: Female voices, Women in literature, Women's right to education.

\section{BASES PARA LA ARTICULACIÓN DE UNA GENEALOGÍA FEMENINA}

Los géneros literarios nobles, que se ocupaban de la teología o la filosofía, la historia y el derecho, ignoraron a la mujer o la llamaban al cumplimiento de sus deberes de esposas y educadoras de la prole. Sin embargo, la literatura, dedicada a la incipiente burguesía, a la aristocracia culta y enfocada a menudo a las lectoras, brinda una oportunidad tanto a la representación de la mujer como a la defensa de sus intereses.

En la ficción literaria cobran voz las mujeres desplazadas, a menudo disfrazadas, las que asumen la defensa de sus libertades en el amor o reivindican su derecho a la educación, las mujeres heroicas o amenazadoras que hacen peligrar el orden impuesto, las mujeres perseguidas, violadas o vendidas por sus propios padres y las que hacen 
votos e ingresan en el claustro. Todas ellas encuentran un espacio de identidad y representación en la literatura.

Sara Salih (2002: 135) apuesta fuerte a la hora de defender un concepto revolucionario de identidad cuando se refiere a Judith Butler para destacar que la capacidad de actuar se potencia al abandonar las quejas sobre las dificultades que pueden existir a la hora de expresarse y defiende que el movimiento realmente revolucionario que permite articular la propia identidad supone asumir el riesgo del ser ontológico.

Tanto Butler como Foucault describieron en su día la formación del sujeto como un proceso que necesitaba ser histórica y socialmente contextualizado antes de ser entendido, y a esta idea contribuye también de manera decisiva Derrida cuando manifiesta que el significado es un hecho que se inscribe dentro de una cadena discursiva sin principio ni fin y que remite a una idea algo abstracta donde el sujeto de la enunciación es soberano sobre la expresión de sus propias experiencias aunque a menudo, como sucede en el caso del discurso de las mujeres que nos ocupan en este trabajo, esté confiado y dirigido por el padre, el tutor o el confesor.

La asunción de la propia voz y del protagonismo discursivo, en el caso de testimonios autobiográficos de mujeres, constituye un gran paso a la hora de definir la identidad porque nos deja ver la construcción de ella misma en primera persona. En ese sentido Butler (1990) se interesa por ver de qué forma el lenguaje contribuye a la construcción de la identidad y por consiguiente al género, admitiendo que el reconocimiento y la expresión del deseo del sujeto es un proceso de significación que conduce a la autoafirmación e identificación del lugar que ocupa el otro. Pero ese proceso casi siempre tiene lugar a través de la aceptación de una diferencia patente entre el uno y el otro.

El lenguaje como proceso de significado nunca se da por cerrado, es un discurso de signos abierto y ya desde el existencialismo sabemos que cuando el individuo se ve obligado a tomar decisiones, asume la libertad de elegir y la responsabilidad sobre su propia vida. Si hablar de sexo es para Foucault una forma de producirlo y controlarlo, de la misma manera hablar del amor y de la mujer, de la igualdad o del derecho a la educación han sido formas de regular los discursos y establecer las normas en la historia y la literatura.

Más que ser, somos hacer, y no hay identidad de género detrás de la experiencia, porque la identidad está ya performativamente constituida por la misma expresión que viene a ser articulada con el fin de alcanzar determinados resultados. Por eso, según Butler, el sujeto y, por extensión, la identidad de género son más bien un efecto del discurso que una causa. Resultan originados por la palabra... Recordemos que al principio fue el verbo, para decir que Dios los creó hombre y, de su costilla, mujer.

La construcción de la identidad femenina está abocada, por consiguiente, desde sus orígenes en nuestro viejo mundo a una posición dialéctica, resultando a menudo ser un efecto del predominio discursivo del sujeto que encarna el poder. Un efecto, pues, y no una causa, como pretendían los discursos misóginos tradicionales.

El sujeto, que ha de constituirse como tal por oposición al otro, está suplementado por una noción relativa al poder que es la de resistencia. El discurso del amor y la reivindicación de los derechos a la educación de las mujeres en la literatura ponen de manifiesto esa resistencia y denotan en cierto modo la hegemonía que la mujer podía alcanzar en el campo de la proyección de los deseos masculinos. Dentro de los discursos hegemónicos la resistencia era capaz de poner en tela de juicio la soberanía del sujeto dominante. En este sentido la propia Salih (2002: 133) destaca en su lectura de Butler que las identidades sexuales no son estables $y$, apelando al significado que 
adquiere el estado de ánimo de la melancolía positiva, desencadenante de un proceso de introspección que hace aflorar la identidad subjetiva, destaca que la reflexión constituye a su vez una manera característica de representación del sujeto femenino.

Según afirma Anne J. Cruz, el acercamiento psicoanalítico puede ayudarnos a reconstruir el elemento femenino en los textos escritos por mujeres para recuperar a la madre de la ley falocéntrica que simultáneamente huye de ella y la margina. Me parecen interesantes las observaciones de esta autora respecto a las relaciones de poder en las que se situaba a las mujeres, clasificadas según sus estados: de soltera, casada, viuda o monja, lo que permitía al varón asegurarse el control social sobre las mismas (Cruz, 1996: 47). No en vano, algunas obras que recogen los argumentos del hablar de los estados de mujeres se convierten en ejemplares para los tratados que se escriben a favor y en contra de ellas. Así Los cuentos de Pembroke de Sidney avisaban de la prudencia que habían de tener los hombres ante las reivindicaciones de las mujeres porque ellas podían hacer de aristocracia monarquía.

Juliette Dor (2004: 48), desde la perspectiva de la Historia de las mentalidades, destaca la ansiedad de género que sufre el hombre, referida por muchos autores para expresar la encrucijada ante la que se encuentran cuando ella reclama un espacio de competencia. El caballero en la literatura es consciente de que para imponer el dominio de su razón patriarcal debe someter y cuidar a la vez a las mujeres que son depositarias de la honra familiar. Uno de los exponentes más antiguos de este comportamiento lo constituye El caballero Zifar, cuyo protagonista corre el peligro de perderse en la infernal laguna que es la dama.

Rosa María Rodríguez Magda (2005: 71), en el contexto de referencia de la arqueología del saber, defiende que no es posible acercarse a la historia de la mujer desde la premisa de un estado de la cosas perpetuo, sino que las mujeres son consideradas como sujetos que toman la palabra cada vez que pueden, en un mundo donde predomina el discurso androcéntrico, para promover y asumir su propio protagonismo. La autora identifica dos tipos de genealogía, más allá de lo que el concepto significa en la lógica hereditaria patriarcal, y señala que la genealogía femenina es entendida en primer lugar como una metodología dispuesta a analizar la construcción de la subjetividad y de la identidad de género a través de la relaciones de poder/conocimiento, mientras que, en segundo lugar, en un sentido más fuerte de reconstrucción de la memoria histórica, simbólica y cultural, la genealogía promovería el autoconocimiento y autorreconocimiento de las mujeres en una lógica nueva que entraña una configuración literaria, política y creativa diferente.

Ella propone que el acercamiento a lo uno/otro debe producirse desde la desconstrucción: analizando cómo la matriz binaria del pensamiento occidental se ha sostenido sobre la base de la opresión de las mujeres porque dicho proceso ha sido incluido en la subjetivación e identidad de género donde se legitiman toda una serie de estrategias de exclusión y dominio.

De la misma manera en que Foucault afirma que el concepto de hombre es un concepto en formación, abierto, el de mujer podría ser abordado con el objetivo de considerar el proceso de construcción de su subjetividad y definir a la vez su identidad. Para ello nos situaremos en los lugares estratégicos del discurso y apelaremos a las ideas desde presupuestos alejados de la lógica esencialista: identificando las convergencias y divergencias discursivas para mostrar lo que deseamos expresar y adueñarnos al fin de nuestra propia identidad y genealogía.

La aproximación pragmática que hacemos aquí, desde el área de la literatura, se centra en propuestas didácticas específicas que tienen en cuenta el compromiso expresado por Foucault en términos de genealogía e historia del presente. De esta forma 
abordamos la crítica social, que el mismo filósofo describe como una ontología crítica, con el análisis de las limitaciones históricas que han sido impuestas a las voces femeninas a la hora de manifestarse en el espacio significativo de experimentación, reivindicación y transgresión que es la obra literaria.

A pesar de que el poder, esencialmente negativo como fuerza represora en las sociedades premodernas, ha operado a través de mecanismos como la ley, la censura o el tabú, no ha conseguido acallar en la literatura las voces de las mujeres que han reivindicado de manera expresa sus deseos y han defendido sus derechos.

Como bien destaca Toril Moi (2008), frente a la orientación fundamental de la crítica anglosajona centrada en la acción de leer como mujeres, las teóricas francesas prefirieron hablar de la oportunidad de escribir como mujeres. Me centraré, por consiguiente, en los textos de la literatura clásica donde las protagonistas expresan sus quejas y reivindicaciones en un sistema donde domina la razón patriarcal. ${ }^{1}$

Las voces de mujeres que se dejan oír en textos escritos por hombres y que en su modalización o modificación, como dice Michel Buttor, aparecen siempre estilizadas, se articulan inevitablemente en un proceso de dialogía, retomando el término de Baktin, entre los que se muestran defensores de los ideales de emancipación femenina y las opiniones contrarreformistas sancionadoras de dichas posturas: no convenía ni siquiera hablar de los estados de las mujeres.

Una fuerte polémica se suscitó tras la revisión de los conceptos y fundamentos de la historia de la literatura inglesa, cuando se puso de relieve que la forma homogénea de interpretación de la producción y recepción de la literatura no había tenido en cuenta las condiciones sociales e históricas reales en las que se había producido; ergo: la mujer, además de producir, sobre todo leía, interpretaba y transmitía oralmente su visión de la realidad. A raíz de esta constatación irrefutable se planteó en Francia la cuestión de si existía una escritura específica de las mujeres, y esto dio lugar a las complejas conceptualizaciones sobre l'écriture féminine de Hélene Cixous y Luce Irigaray o a los experimentos de Monique Wittig.

Amelia Valcárcel (1994: 11) en Sexo y filosofía destaca que el hombre considera lo masculino como lo propio de la especie, mientras que lo femenino se construye e identifica como característico ya sea por inversión o por exclusión. En ese sentido la dimorfia sexual articula o sexúa el pensamiento, el poder y hasta la ontología. Por esa razón el feminismo según Varcárcel (1994: 63) obliga a redefinir la historia de la cultura, las relaciones con la naturaleza, los rangos y la misma comunicación. En la línea de Adler, más que en la de Freud o Jung, Valcárcel (1994: 72) asegura que todo conflicto es un conflicto de poder o con un poder y que lo que da sentido a la vida de los individuos es el deseo de hacerse valer ante los sentimientos de inferioridad, y añade que semejante trama resultaría reforzada por cualquier pedagogía.

Voces literarias Dentro y FUera del Claustro: Teresa de CARTAgena, Teresa DE JESÚS Y SOR JUANA INÉS DE LA CRUZ

Prestando atención a los testimonios de mujeres que escriben en primera persona para construir su identidad y reivindicar el derecho a la educación y la escritura, aun desde la reclusión del convento, consideramos el caso cada vez más conocido de Teresa

\footnotetext{
${ }^{1}$ Para revisar todas las aproximaciones críticas a la materia véase Fariña Busto y Suárez Briones, 1994.
} 
de Cartagena. ${ }^{2}$ Esta mujer de familia conversa descendiente del obispo Pablo de Santa María estuvo aquejada de graves dolencias, entre ellas la pérdida del oído, que como ella misma reconocía con pesar, la fue aislando del ruido placentero de las cosas mundanas volviéndola a la contemplación interior.

Teresa escribió dos obras que han llegado a nuestros días: la Arboleda de enfermos y la Admiración operum dei. En la primera, la autora finge que el furioso torbellino de las humanas pasiones la ha arrojado a una isla desierta donde encuentra el consuelo del Evangelio.

La importancia de esta primera escritora, oficial ya, de la lengua castellana no destaca solo por esto, sino debido a que su obra puede ser entendida, desde la perspectiva de género que abordamos en nuestro trabajo, como el testimonio sincero de una escritura comprometida con la defensa del derecho de las mujeres a la escritura. Desde el comienzo habla en femenino y se manifiesta como mujer letrada, asegurando que llegó a estudiar en Salamanca, y se pronuncia a favor de la naturaleza de las mujeres frente a la supuesta inferioridad que les atribuían sus congéneres.

Ya en su dedicatoria a doña Juana de Mendoza, mujer del dramaturgo Gómez Manrique, ella se defendía de las acusaciones de plagio y del escándalo que había provocado la publicación de la Arboleda de enfermos. En su defensa dice que muchas veces tanto hombres como mujeres, prudentes los unos y discretas ellas, habían podido maravillarse de que hubiera escrito un tratado tan docto, y, en un acto de necesaria falsa modestia, afirma que pudo suplir su flaco mujeril entendimiento mediante la gracia divina, que tomó a la fuerza su mano cuando lo escribió. Esa grandeza divina podría otorgar a su juicio la misma capacidad de entendimiento a mujeres y a hombres, ya que el entendimiento varonil no era una cualidad innata sino un don que les proporcionaba Dios. Con ese razonamiento Teresa toma como punto de partida la omnipotencia de Dios y declara que, de la misma manera en que la había dotado de talento y capacidad a ella para escribir un tratado, podía repartir la igualdad intelectual entre otros hombres y mujeres.

Teresa de Cartagena definió la Arboleda de enfermos como un tratado de consuelo espiritual cuyo objetivo era ayudar y acompañar, mediante la escritura, a aquellas personas enfermas que, como ella misma, ya no podían ser tratadas por la ciencia. Dentro de la tradición de La consolación de Boecio, la autora ofrece una propuesta de cura espiritual que encuentra en la imagen de la arboleda la medicina para su mal.

El deseo de conocer en profundidad y de demostrar por extenso los secretos de la fe cristiana caracterizó la obra de muchos conversos de grado. Como ocurre con los abecedarios espirituales, había obras que estaban plagadas de avisos para evitar posibles sospechas sobre la religión que pudieran haber practicado sus antepasados.

Dentro del discurso de la salud y la enfermedad no queda otro remedio que aludir a la extrapolación que estos términos tenían desde el campo del padecimiento físico al de la enfermedad espiritual, no pocas veces identificada como el pecado de aquellos que no terminaban de abrazar definitivamente la fe cristiana. Paradójicamente, la autora entiende la enfermedad como una atribución divina, que requiere como primer paso la aceptación y el reconocimiento de la propia dolencia antes de encontrar «la verdadera salud». El camino que lleva al conocimiento profundo de Dios pasa por hacer significativo su cuerpo de mujer que se busca en lo infinito, y en esa misión todo el sufrimiento y el dolor físico adquieren una connotación positiva porque acercan a la

${ }^{2}$ Existe una edición y estudio reciente a cargo de $\mathrm{M}^{\mathrm{a}}$ del Mar Cortés Timoner, 2004. Esta edición ha estado precedida por la pionera de Lewis J. Hutton (1967) por la que citamos, a partir de ahora indicando únicamente el número de página que corresponda. 
enferma a la salvación. Teresa de Cartagena afronta un proceso de autoconocimiento significativo donde el eje es el cuerpo femenino y recomienda al lector la eficacia de su terapia: «que venga a la escuela del Dios de las paçiençias» (141), la única manera a través de la cual llegará a conocerse a sí misma.

Parece que estamos ante uno de los testimonios más actuales de la pedagogía cuando atendemos a las recomendaciones que hace para sobrellevar las penalidades de la vida: facere y docere, y admite que le conviene trabajar buscando letrados que sean doctos en esas ciencias. Se refiere a la combinación de paz y ciencia que haría mecedora de esas cualidades a su propia escritura. Esas mismas palabras inspiran el esfuerzo y la constancia que caracterizan años más tarde la obra de Teresa de Cepeda y Humada.

Confiesa la monja - y ese término no deja de ser polisémico a la hora de aplicarlo a individuos procedentes de linajes judeoconversos - que, hasta abrazar la fe cristiana, había querido solazarse con conversaciones profanas - seglares, dice ella-, pero una vez tomada la decisión de profesar, asegura, había abandonado ese dañoso querer. Perdido el sentido del oído y alejada de la gente, su lengua parlera ya dejaba de hablar, abandonando el deseo de las cosas mundanas para preocuparse por su salud física y sobre todo espiritual. Y escribe Teresa cómo llegó a aceptar la situación de aislamiento del mundo para convertirse hacia la oración y la contemplación que garantizaría la seguridad de su alma, recordando la voz que le decía:

Oye fija, e acata e ynclina tu oreja, oluida el pueblo tuyo y la casa de tu padre. E como las primeras palabras tanto y tanto me aperçiben que oyga y pare mientes e yncline mi oreja, da a entender que las syguientes de oluidar el pueblo mío e la casa de mi padre otra sygnificaçión trahen de la que luego en sý representan. [C]a para lo entender ansy synplemente como sue[n]a, asaz abastaua vna destas amonestaçiones; mas todas tres juntas, oýr, acatar e ynclinar la oreja, claro me muestran que con toda diligençia deuo myrar no solamente lo que dizen las mesmas palabras, mas la sentençia que consygo trahen. Pero bien es de tener primero lo que dize para mejor conosçer lo que quiere dezir, ca dize: Oluida el pueblo tuyo y la casa de tu padre. E non manda olvidar el padre, mas la casa suya. E claro es que no se dize por la casa material, ca no tiene en sý razón de oluidar nin remenbrar, mas por la familia (44-45).

Siguiendo dentro del ámbito de referencia de las comunidades conversas encontramos testimonios singulares y significativos para estudiar la construcción de la identidad del «sujeto» femenino en los siglos XV y XVI. ${ }^{3}$ Poco antes de que la Contrarreforma impusiera un modo de vida mucho más controlado donde los propios vecinos se convertían en sospechosos y delatores, aparece otra mujer de ascendencia conversa que no termina de encontrar su lugar en la sociedad, que ama la literatura y que decide profesar para poder dedicarse al cultivo de la vida interior sin sustraerse al influjo de la acción y la voluntad para influir en la realidad que la rodea. Se trata de Teresa Sánchez de Cepeda y Ahumada. Esa mujer que sufre también una enfermedad y que en el camino hacia uno de sus retiros recibe de su padre el Tercer Abecedario de Osuna, donde se aconsejaba: examina, hazte experto, vigila todas tus obras...

Rosa Navarro Durán, en la introducción a La vida y Las moradas (en Teresa de Jesús, 1984: x), reconoce que Teresa «tiene dentro de sí una fuerza y ve con claridad tantas cosas que a veces estalla su indignidad o su impotencia».

Al igual que su precedente, esta joven declara que tuvo dificultades para renunciar a las amenidades de la vida social y pasaron años hasta que se produjo su verdadera conversión ya mediado el siglo XVI. Ella misma en La vida siempre advierte

${ }^{3}$ El trabajo de Rita Ríos de la Llave (2010) profundiza sobra el linaje converso de la monja. 
que el demonio la tentaba induciéndola a conversaciones con gentes que no le convenían y que a la edad de 14 años prefería la amistad de personas mundanas, tomando daño de una parienta de la casa de «livianos tratos». Reconoce su «sagacidad para cualquier cosa mala», que la llevaba a buscar, aunque era reprendida por su padre y hermana mayor, las malas compañías (Teresa de Jesús, 1984: 9, 27, 33, 34).

La joven abulense habla de sí con una espontaneidad que poco tiene que ver con sus meditaciones ascéticas de madurez, y precisamente por ello sus palabras alcanzan estatus de testimonio, único y sincero, cuando se reconoce boba unos días y otros inquieta o alborotada (Teresa de Jesús, 1984: 245-255).

Mucho más segura que Teresa de Cartagena de que la escritura permite el acceso a la cultura y da voz a la mujer, quiso defender el conocimiento a través de la lectura y siempre declaraba que prefería confesores letrados a los que apenas sabían leer. Teresa conoce bien a sus interlocutoras y bien sabe lo que desea transmitirles, hasta el punto de que constantemente alude a ellas con frases donde predominan las fórmulas coloquiales para convencer bromeando y provocar la risa, riéndose incluso de sí misma.

Ella reconoce las dificultades que tienen las mujeres en una sociedad regida por un principio tan discutido y frágil como la honra y en el Camino de perfección afirma:

¡Oh, válame Dios, hermanas si entendiésemos qué cosa es honra y en qué estar perder la honra! Ahora no hablo con vosotras — que harto mal sería no tener entendido esto-, sino conmigo, el tiempo que me precié de honra sin entender qué cosa era, y íbame al hilo de la gente por lo que oía (Tersa de Jesús, 1982: 311).

En 1559 tiene Teresa su primera visión intelectual de Cristo, a la que seguirían otras visiones imaginarias, y en ese mismo año se publica Los siete libros de la Diana, obra del músico y poeta portugués, también de origen converso, Jorge de Montemayor. De seguro que las aventuras de Felismena de Vandalia hicieron las delicias de la joven Teresa, tan aficionada por su madre a novelas de caballerías y otras obras de aventuras.

La literatura profana alterna con la arraigada tradición de las obras literarias visionarias que data de la Edad Media y que con la edición de la Visión deleitable de 1485, de Alfonso de la Torre, judío converso que se inspira en la Guía de perplejos de Maimónides, divulga el saber enciclopédico propio del trivium y el cuadrivium medievales. En ese contexto cualquier visión inducida por el sueño alegórico podía ser sospechosa de herejía, y este hecho afecta de igual modo a la literatura no religiosa, que empieza a dar muestras contrarreformistas en obras compuestas a lo divino.

Teresa de Jesús depende de sus confesores para escribir y no se arredra aceptando con falsa modestia la posible inferioridad de la mujer con tal de sacar a la luz sus ideas con el estilo más personal, subjetivo y moderno que se conocía hasta entonces. Ya decía que escribía para mujercitas, como ella, flacas y con poca fortaleza.

Un siglo después sor Juana Inés de la Cruz en su Respuesta a Sor Filotea defiende su natural inclinación al estudio y aboga por la enseñanza de las mujeres, que debía correr a cargo de doctas ancianas a fin de evitar los peligros que conllevaba un trato demasiado familiar con los hombres. Sor Juana intenta ganar el espacio de la educación para las mujeres cuando se apoya en san Jerónimo y recomienda a Leta que aleccione personalmente a su hija.

Sor Juana, que nació en una alquería cercana a la ciudad de México, sorprende a la corte novohispana con su precoz sabiduría y busca refugio en el convento de Santa Paula para poder proseguir sus estudios solitarios entregada a la indagación de la naturaleza del hombre y del cosmos universal.

Penetrar en la mentalidad novohispana e identificar las expectativas de realización que pudieran tener las mujeres seglares o religiosas, así como calibrar cuáles eran las 
oportunidades que la sociedad les ofrecía en la corte virreinal es una empresa acometida en los últimos años por reconocidos expertos. ${ }^{4}$ Sabido es que la voz de sor Juana se eleva desde la periferia del imperio para acometer la defensa de la mujer. Ya advierte Electa Arenal (1991: 131) que sor Juana relee, reescribe, revisa, rompiendo convenciones, y cómo esta práctica entroncaba con la larga tradición de la querelle des femmes pero ella insiste precisamente en un aspecto sobre el que los tradicionales defensores de las mujeres habían pasado de puntillas: su derecho a la educación y a la enseñanza en las mismas condiciones que el hombre. $\mathrm{Y}$ al hacer de este argumento el centro de su defensa, sor Juana se revela como una preilustrada que, con seguridad, por la afluencia de cartas que mantenía con Europa, estaba al día de las nuevas posturas de los filósofos franceses sobre la educación de las mujeres en todas las disciplinas e incluso conocía la especial dedicación al estudio de mujeres como la reina de Suecia o los progresos de la discípula de Descartes Giuseppa Eleonora Barbapiccola.

Si ya Electa Arenal en su día hablara sobre epistemología femenina en sor Juana (Arenal, 1991: 131), ${ }^{5}$ destacando la elección de heroínas mitológicas características por la rebelión contra el orden patriarcal y el consiguiente castigo que sufren Perséfone, Aretusa o Nictimine, reconociendo a la vez la familiaridad con que sor Juana trataba los argumentos a favor de sus congéneres; Aralia López González (1993: 346), por su parte, destaca la distinción que en la Sátira filosófica contra los hombres necios se lleva a cabo entre sexo como elemento biológico y natural y género como construcción histórica y cultural, lo que hoy se denomina en la reflexión feminista el sistema sexo/género. Para sor Juana la condición femenina no es una esencia sino un producto condicionado por sus propias acciones. Así en los villancicos a santa Catarina de Alejandría la décima musa explicita que la pertenencia al sexo femenino no supone carencia alguna de facultades intelectuales: De una mujer se convencen / todos los sabios de Egipto / para prueba de que el sexo / no es esencia en lo entendido... En la misma tónica se hace eco en la Respuesta a sor Filotea de la Cruz de un elenco de mujeres sabias como Débora, Saba, Abigail, Hipasia o Catarina.

Otros investigadores se han referido a su obra como modelo epistemológico ejemplar sobre los mecanismos de la verdad. Rafael Ruiloba (1999) afirma que las redondillas de la Sátira filosófica contra los hombres necios nos hablan sobre la relación dialéctica entre verdad y moral en las relaciones interpersonales. La verdad para sor Juana no es importante en sí misma, sino que es parte del movimiento del ser para labrarse una conciencia de sí. La verdad es para ella valor moral y, de acuerdo con los principios de la ciencia nueva de Gian Battista Vico, postula la unidad de pensamiento y expresión.

El rasgo esencial de la personalidad de sor Juana es la curiosidad intelectual: fue ecléctica por vocación y hasta cierto punto escéptica; cada escuela de pensamiento le podía proporcionar un campo de reflexión y, aunque sospechaba la existencia de muchos datos inasequibles a su conocimiento, sabía que no sabía, se dedicaba con delectación al estudio de temas herméticos (Paz, 1982; Trabulse, 1974). Sor Juana lleva a cabo su intento de conocer principalmente en su Primero sueño, poema de la más complicada factura culterana, cuyo tema es precisamente la indagación de las posibilidades y límites del conocimiento humano. Pero sor Juana quiso intervenir también en materia de teología, motor de todos sus estudios, y a instancias de su director espiritual redacta la famosa Carta

\footnotetext{
${ }^{4}$ Véase Codding, 1995. Un trabajo más actual que recoge el enfoque de género es el de Julia Lewandowska, 2012.

${ }^{5}$ En un trabajo anterior, Arenal (1983: 101) destaca las referencias de sor Juana al linaje de María, que entronca con la civilización matriarcal y la diosa engendradora para argumentar a favor del derecho de la mujer, y específicamente el suyo, a estudiar y a escribir. Esta perspectiva es actualizada por Linda Eagen, 1993.
} 
atenagórica, ${ }^{6}$ una epistola digna de la diosa Atenea, donde, al hilo de un sermón del jesuita portugués Antonio de Vieyra, polemiza sobre las finezas de Cristo y los favores negativos que hace al creyente. La monja demuestra allí no solo su pericia argumentativa, sino también un rechazo radical a determinadas concepciones al uso a través de intervenciones irónicas que manifiestan una valiente actitud. Partiendo de la idea de que bajo el envoltorio de la crítica a un sermón se encuentra la defensa personal de sus postulados, podemos decir que luchó con todas las armas que tenía a su alcance por la independencia intelectual.

La historiografía oficial indica que a raíz de la Respuesta a sor Filotea ${ }^{7}$ Sor Juana se vio abandonada ante los poderes que la asediaban, y aun así tuvo arrestos para emprender su defensa y contestar a su confesor y guía espiritual, el jesuita Antonio Nuñez de Miranda, a quien le increpaba: «si no gusta en favorecerme no se acuerde de mí» (en Ruiloba, 1999: 51).

Ruiloba difiere de la interpretación clásica de Octavio Paz en Sor Juana Inés de la Cruz o las trampas de la fe, cuando cree que la constante preocupación del confesor por su pupila era un intento declarado de preservarla de males mayores. Los desplantes de sor Juana en esta última carta, hallada en 1981 e integrada en el apéndice de la tercera edición de Paz, no abundan en esa interpretación. ${ }^{8}$ Sor Juana le recuerda a su confesor cómo la había obligado a malear la letra y defiende su independencia cuando le inquiere sobre la obligación de parentesco, crianza o prelacía que pudiera tener con ella en un estado de cultura que la anatemizaba por su condición de mujer, de hija ilegítima, criolla, y, sobre todo de persona inteligente, capaz de ejercer con maestría la pintura, la música, la filosofía y el teatro (en Ruiloba, 1999: 53).

Por su parte Jesús García Álvarez (1997) se distancia de la hipótesis de Paz y Puccini, quienes consideran a sor Juana víctima de una enemistad entre los prelados de México y Puebla e instrumento de una secreta venganza de Santa Cruz, que habría publicado la crítica al sermón de Vieyra para atacar a Aguiar Seijas y a sus amigos jesuitas, toda vez que había sido desplazado del arzobispado al que pretendía. García Álvarez no especula con las razones que pudieron llevar a sor Juana al más absoluto silencio a la par que se producía el declinar del imperio criollo. Él ve en la obra final de sor Juana la indeleble huella del desengaño, el sello inestimable de la melancolía. Había llegado la noche oscura del espíritu, la hora de la mortificación.

La lectura de la obra de sor Juana solo puede ser entendida como un producto de la modernidad donde el arte ofrece una marca fronteriza entre ciencia y religión como gozne que combina el aparecer de la conciencia y el cerco hermético que la religión quiere colonizar. Sor Juana elige el sueño dentro del arte, la visio nocturna con tintes de anábasis para que su alma peregrina inicie la búsqueda trascendental del conocimiento. El sueño vehículo de evasión y reflexión le asegura un espacio de intimidad, de fuero interno, que se presta a la contemplación y a la meditación, una visión deleitable cuando aparece en clave de arte. Un arte moderno, porque el objeto estético refleja la especulación teórica a la que obedece, presenta una exacerbación de los códigos lingüísticos y se articula en función de la ironía encubierta razonable - que diría Wayne C. Booth - y de otras conexiones encubiertas inaceptables, desembocando en la conclusión manifiesta de que no puede

\footnotetext{
${ }^{6}$ Véase el capítulo de Octavio Paz (1982: 511-533) «Carta de más», que trata sobre este escrito de sor Juana, de noviembre de 1690.

${ }^{7}$ Tres meses después de que se hiciera pública la Carta atenagórica, sor Juana publica la Respuesta a sor Filotea de la Cruz. Bajo ese nombre se identifica al obispo de Puebla Fernández de Santa Cruz, quien le había escrito la Carta de sor Filotea de la Cruz, donde el obispo enfrentaba a sor Juana con el problema de su vocación. Véase Paz, 1982: 534-550.

${ }^{8}$ Esta carta fue editada con el título de Autodefensa espiritual. Carta de la madre Juana Inés de la Cruz al Rev. Maestro Antonio Núñez de la Compañía de Jesús por Aureliano Tapia, Impresora Monterrey, 1986.
} 
alcanzar el vuelo del conocimiento ni por contemplación ni por meditación. Estamos ante un nuevo Faetón, el ser caído, aterrado, el héroe melancólico que solo se reafirma en su propia creación reflexiva y ha de rendir cuentas por su condición soberbia, siendo condenada al ostracismo.

El espacio elegido por sor Juana remite a la vida intrauterina, un espacio que reivindica la escritura conscientemente femenina donde reclama su derecho a la propiedad imaginada. Desde los márgenes que permite la sociedad colonial criolla defiende el derecho a construir un discurso en las mismas condiciones que el hombre. Con la elección de la fórmula del sueño sor Juana denuncia la imposibilidad de tratar ciertos temas que le interesaban sin correr el peligro de ser acusada de herética. Frente al cartesiano «pienso, luego existo», ella arguye: «Yo sueño», y titula así su obra maestra: Primero sueño... haciendo más sólida la tesis de que el feminismo parte del reconocimiento intrínseco a la modernidad de un sentimiento de enajenación y vacío del yo frente al otro.

VOCES LITERARIAS PROTAGONISTAS DE LA FICCIÓN NOVELESCA: CORTESANAS Y PASTORAS

Cambiando de tercio ahora nos adentramos en la ficción literaria para atender a la voz de una señalada protagonista femenina, tan identificada con su autor que se muestra dispuesta a cumplir sus deseos sirviéndole hasta para engendrar una criatura suya. Estamos hablando de Aldonza, conocida en Roma como Lozana andaluza, una mujer cordobesa que, saliendo del Zocodover, y tras accidentado periplo, toca puerto en Livorno para continuar su peregrinación hacia Roma, la ciudad del Amor, donde dispondrá de autonomía para ejercer los oficios propios de las cortesanas, pícaras y alcahuetas, gobernando con libertad y generosidad su propia casa.

Publicada en 1528 en Venecia bajo el título de Retrato de la lozana andaluza, ${ }^{9}$ este conjunto de mamotretos fue compuesto por Francisco Delicado, a quien se ha relacionado con el círculo de judeoconversos. Este autor y editor, que recibió órdenes sagradas, pertenecía a una clase de intelectuales clérigos que aún no temían dedicarse a la difusión y composición de obras profanas, caso que deja de producirse a partir de mediados de siglo, por el peligro que entrañaba ante el celo de los tribunales de la Inquisición. Como buen humanista, Delicado defiende el uso de la lengua vernácula cuando expresa en su «Apología» que, «siendo andaluz y no letrado», conformaba su hablar al sonido de sus orejas, que era la lengua materna y el común hablar entre mujeres (248). Con un sentido que podríamos calificar de preformista de la realidad figurativa, el autor y coprotagonista de su propia obra emprende el retrato de esa mujer, caracterizada por su inteligencia y saber, que desde la niñez tuvo ingenio, memoria y vivez, siendo amada de los suyos y aguda en servirlos (37). Buen conocedor de la literatura de este género, el que realizó incluso dos ediciones de La Celestina, influyó en los textos italianos de Aretino donde proliferaban personajes comunes o en la Propaladia, la Tinellaria y la Comedia Serafina de Torres Naharro.

Aldonza ya tenía hijos de Didomedes, primogénito de un rico comerciante con el que vivía amancebada, pero tuvo que renunciar a su acomodo cuando el suegro quiso deshacerse de ella y, despojándola de sus hijos y pertenencias, la echó al mar. Pronto comprende la protagonista que debe usar toda su argucia para ver cómo se comportan

${ }^{9}$ Aunque citaremos por la edición de Bruno Damiani (1984, Barcelona, Planeta), a partir de ahora indicando únicamente el número de página que corresponda, hay una reciente a cargo de Folke Gernert y Jacques Joset, Madrid/Barcelona, Galaxia Gutenberg/Círculo de Lectores, 2013. 
las otras mujeres de Roma, con el objetivo de conseguir la libertad y el gobierno de su propia vida. Allí encuentra a otras andaluzas y se une a las judías Mira, Engracia, Perla, Jamila, Rosa, Cufa, Cintia y Alfarutia, que le enseñaron los múltiples oficios del cuidado de la salud en el sentido más amplio del término, llegando a ser conocida como la Avicena de la capital.

Es cierto que el carácter dialógico de algunos textos de los siglos XV y XVI da pie a una lectura más abierta que tendría en cuenta la recepción de los mismos a manos de las mujeres de su tiempo. Baktin defendía que las voces cobraban protagonismo y, si bien en el caso que nos ocupa son de ficción, creadas para la literatura por un autor simpatizante, es inevitable descubrir en ellas reivindicaciones que tuvieron su correlato en la sociedad en la que se escuchaban. El sentido negociado de la propia obra y del destino de los personajes se evidencia en muestras de la literatura prerrenacentista que todavía no habían sufrido la censura y el control ideológico contrarreformista.

Así ya en la tercera parte de la novela el autor, que ha intervenido reiteradamente en la trama, asegura que quiere dar fin a la obra y, cuando visita la casa de la Lozana, añade: «Cómo, estando la Lozana, diciendo lo que le convenía hacer para tratar y platicar en esta tierra sin servir a nadie, entró el autor callando, y disputaron los dos». El autor busca una viuda que lo haga padre y ella le responde:

¿Sabéis, señor, qué he pensado? Que quizás Dios os ha traído hoy por aquí. A mí me ha venido hoy mi camisa, y quiero ir esta tarde a la estufa, y como venga, que peguemos con ello, y yo desta complisión, que como yo quiero, luego encajo, y mirá, llegar y pegar todo será uno. Y básteme a mí que lo hagáis criar vos, que no quiero otro depósito. Y sea mañana, y veníos acá, y comeremos un medio cabreito, que sé yo hacer apedreado (175).

La protagonista es consciente del retrato que le hace el autor y se preocupa de salir bien parada cuando trata con su amigo Silvano de los pormenores. Sin rubor, afirma: «Yo doy muchas gracias a Dios porque me formó en Córdoba más que en otra tierra, y me hizo mujer sabida y no bestia, y de nación española y no de otra» (193).

Lozana clama cuando las cosas se ponen feas por el derecho a que se les reconozca una pensión a aquellas prostitutas que han dejado el oficio y emprende la defensa de su clase:

quiero decir que cuando a las perdidas y lisiadas y pobres y en senectud constitutas, no les dan el premio o mérito que merecen, serán causa que no vengan munchas que vinieron a relevar a las naturales fatigas y cansancios y combates, y esto causará la ingratitud que con las pasadas usaron, y de aquí redundará que los galanes requieran a las casadas y a las vírgenes de esta tierra y ellas darán de sus casas joyas, dinero y cuanto ternán a quien las encubra y a quien las quiera, de modo que quedarían los naturales ligeros como ciervos asentados a la sombra del alcornoque, y ellas contentas y pobres, porque se quiere dejar hacer tal oficio a quien lo saben menear (184).

Desde luego el uso del discurso da rienda suelta al pensamiento aun cuando en determinadas época la censura externa y la propia autocensura lo modelaran. La fuerza motriz que incita a poner palabras al propio pensamiento es el deseo, deseo de participar en el discurso, deseo de ampliar la conciencia y de influir en la sociedad, deseo de conocerse mejor a sí mismas, como lo demuestran los escritos de memorias, diarios y confesiones en primera persona de las mujeres en la literatura.

El deseo permite expresar la igualdad y la diferencia que podemos percibir en las voces de algunas protagonistas de novelas pastoriles como Menina y moza de 
Bernardim Ribeiro, Selvagia o Felismena de Los siete libros de la Diana de Jorge de Montemayor, cuando expresan con melancolía las circunstancias que conforman su destino e identidad. Otras protagonistas como las peregrinas o las pícaras transmiten valiosa información sobre la mujer en la sociedad coetánea. A menudo las protagonistas femeninas pastoriles que protagonizan un discurso emancipatorio, como Marcela en el Quijote, tienen hacienda, aunque sea pequeña, y defienden su libertad. Otras, con menos suerte, aparecen travestidas asumiendo la subversión o parodia del orden impuesto para aprovecharse de una serie de oportunidades descargando conflictos de poder en la lucha por definir su identidad, que a menudo está sometida tanto a procesos de reproducción como de anulación y que suele desembocar en ese estado de melancolía heterosexual a la que hacía referencia Judith Butler (en Salih, 2002: 60).

Selvagia, la más experimentada de los personajes femeninos de Los siete libros de la Diana del poeta y músico portugués, articula el argumento principal que dará pie a las reivindicaciones femeninas de gran número de novelas pastoriles, desde el «Canto de Florisia», ${ }^{10}$ incluido en la Diana de Gil Polo y en la de Texeda, hasta la invocación del alma de La Diana a lo divino de Bartolomé Ponce.

Así de expresiva se manifiesta la pastora:

Mas con todo esto, creo que no hay mas baxo estado en la vida que el de las mujeres; porque si os hablan bien pensais que están muertas de amores; si no os hablan, creeís que de alteradas y fantásticas lo hazen; si el recogimiento que tienen no haze a vuestro propósito, teneíslo por ypocresía; no tienen desemboltura que os parezca demasiada; si callan dezís que son nezias; si hablan que son pesadas; y que no ay quien las sufra; si os quieren todo lo del mundo, creeís que de malas lo hazen, si os olvidan y se apartan de las ocasiones de ser infamadas, dezís que de inconstantes y poco firmes en un propósito. Assí que no está en más pareceros la mujer buena o mala que en acertar ella a no salir jamás de lo que pide vuestra inclinación (López Estrada, 1970: 38-39).

Belisa, por su parte, asume la defensa de la mujer en La Diana enamorada:

Queremos nosotras, D. Felis, ser aventajadas, y en ello mostramos nuestro valor, subjetándonos de grado a la voluntad y saber de los hombres, pero no faltan mujeres que puedan estar a parangón con los más señalados varones; que aunque el oro esté escondido o no conoscido, no deja de tener su valor (en Ferreres, 1993: 235).

Luego inicia la canción de Florisia —donde se cifran todas las quejas y reivindicaciones femeninas que más tarde harán suyas no solo las protagonistas de Texeda en La tercera parte de la Diana, sino también las célebres redondillas de la Sátira filosófica contra los hombres necios de sor Juana Inés de la Cruz-:

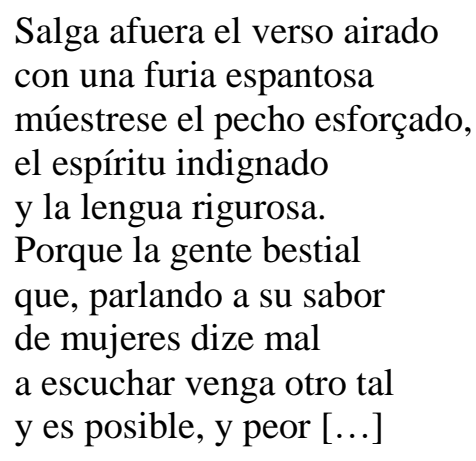

${ }^{10}$ Georgina Sabat de Rivers (1982: 40-41) anota este hecho en su «Introducción» a Inundación castálida. 
y es que como malvados al falso amor de costumbre están contino vezados, ser muy de veras amados les parece pesadumbre, Pero donoso es de ver que el de más mala manera en no estar una mujer toda hecha a su placer les dize traidora y fiera. Luego vereis ser nombradas desdeñosas las modestas, y las castas malcriadas soberbias las recatadas y crueles las honestas. Y ansí los hombres letrados con engañosa cautela, soberbios en sus estados, por no ser aventajados nos destierran de la escuela (235).

Para Julia Kristeva, como señala Toril Moi (2008: 12), está claro que no es la condición biológica sexual de la persona sino la posición que esta asume respecto a la manera de expresarse como sujeto lo que determina su potencial revolucionario rechazando la dicotomía entre masculino y femenino como metafísica.

Por su parte, el feminismo crítico francés ha contribuido poderosamente a esclarecer las cuestiones en juego respecto a la opresión vivida por la mujer durante siglos, la construcción de su identidad sexual y la reivindicación de la diferencia y especificidad del lenguaje femenino, así como su relación con la escritura. De esta manera la voz de la mujer cobra sentido en la escritura y la escritura representa el ámbito de la diferencia para recrear un lenguaje femenino. De nuevo irrumpe con toda su fuerza la revolución de la lengua poética, donde sexualidad y textualidad se abren a una manera nueva de interpretación de las voces y escrituras.

La mujer, definida en el margen, en los límites de la sociedad, pertenece al ámbito de la naturaleza y se caracteriza siempre como una lacra, un defecto, una falta...; por eso, cualquier esfuerzo por recuperar el sentido, por apropiarse de la realidad y defender su posición es entendido como subversión. Bien es cierto, como reconoce Irigaray (1985), que una mujer sin referentes, sin espejo, difícilmente puede erigirse para reflejar su construcción como sujeto; sin embargo, es en esa carencia o usurpación de la ocasión de hablar, precisamente, donde se sitúa una nueva disposición hacia el discurso propio. Como sucedía en el caso de los místicos, donde el alma a través de una vía iluminativa tomaba la palabra en femenino: en una noche oscura, con ansias, en amores inflamada... De esa manera cuando la incipiente Ilustración se reconoce en el «Cogito ergo sum» de Descartes, la mejicana sor Juana Inés de la Cruz, que se ve desplazada y obliterada, siente la necesidad de trasgredir y, situándose más allá del plano de lo simbólico, se reafirma paradójicamente en la tradición de la noche de San Juan diciendo esta vez: «Primero sueño...».

De todas formas estamos hartas de ver, tanto en la realidad y en la ficción como en cualquier momento de descuido, cansancio, sueño, desvarío o pérdida, más si se produce a horas intempestivas, las circunstancias más variopintas pueden servir de condicionante para culpabilizar a la mujer víctima de la violencia masculina. La opresión patriarcal y la misoginia imperante denuncian diferentes actitudes de rechazo o 
culpabilización por el sexo, reacción que aumenta paralelamente frente a sublimación de la mujer y el deseo del hombre de que permanezca sujeta a su voluntad (Salih, 2002: 26). Todas estas actitudes son apreciables en el caso de la ficción novelesca, el teatro y la poesía porque se convirtieron en asunto de polémica en cualquier ocasión, llegando a convertirse en tópico e incluso dando lugar a la interiorización de esas mismas posturas por parte de las mujeres que sufrían y se sintieron culpables por el hecho de ser mujer... ¡cuanto más si se dormían! Tal fue el caso de la protagonista de La soledad entretenida, obra contrarreformista de Juan Barrionuevo y Moya (1638, I: 183, 189), cuando, tras ser secuestrada y violada, cuenta:

que viendo que por todas las vías era resistido, y menospreciado, y que por todos los medios humanos no había orden de hacerme degenerar un punto de quien soy, se resolvió en conseguir por la fuerza lo que sus torpes palabras y promesas mentirosas no habían podido alcanzar.

Y más adelante:

y no siendo partes de mi ánimo y fuerzas para defenderme, me entorpecí de manera que aunque me determiné a dar voces a Almanzor para que me favoreciese en aquella angustia no pude, por sentirme tan impedida y trabada la lengua que no podía articular siquiera palabra. Finalmente no sé cómo me hechizó o endemonió que arrebatándome me llevó por los aires mediante algún demonio a la sepultura hueca del despeñadero... donde me puso para algún maleficio (que no entiendo) de la forma que vos señor me hallaste; habiéndome primero despojado de mis ropas no sé de qué manera, no dónde.

Pero entrar a analizar los orígenes, causas y consecuencias de obras contrarreformistas como esta, que, a pesar de su divertido título, encierra los más perversos argumentos misóginos y racistas merecería un capítulo aparte. Vale.

\section{OBRAS CITADAS}

Arenal, Electa (1983), «Sor Juana Inés de la Cruz: Speaking the Mother Tongue», University of Dayton Review, XVI, 2, pp. 93-105.

Arenal, Electa (1991), «Where Woman is Creator of Wor(1)d, or, Sor Juana's Discourses on Method», en Stephanie Merrim (ed.), Feminist Perspectives on Sor Juana Inés de la Cruz, Detroit, Wayne State University Press, pp. 124-141.

Barrionuevo y Moya, Juan (1638), Soledad entretenida en que se da noticia de la historia de Ambrosio Calisandro, Écija, Luis Estupiñán.

Butler, Judith (1990), Gender Trouble: Feminism and the Subversion of Identity, Londres/Nueva York, Routledge.

Castillejo, Cristóbal (1960), Diálogo sobre las mujeres y Sermón de amor, Madrid, Espasa Calpe.

Codding, Mitchell A. (1995), «Sor Juana Inés de la Cruz and Her Worlds: an Exhibition at The Spanish Society of America», Colonial Latin American Review, IV, 2, pp. 19-40.

Cortés Timoner, $\mathrm{M}^{\mathrm{a}}$ del Mar (2004), Teresa de Cartagena. Primera escritora mística en lengua castellana, Málaga, Universidad de Málaga.

Cruz, Anne J. (1996), «La búsqueda de la madre: psicoanálisis y feminismo en la literatura del Siglo de Oro», en Alain Saint Saëns (coord.), Historia silenciada de la mujer: la mujer española desde la época medieval hasta la contemporánea, Madrid, Editorial Complutense.

Damiani, Bruno (ed.) (1984), La Lozana andaluza, Francisco Delicado, Barcelona, Planeta. 
Dor, Juliette (2004), «Le Lecteur résistent en quête dàutres voix de la femme mediévale», en Guyonne Leduc (dir.), Nouvelles sources et nouvelles méthodologies de recherche dans les études sur les femmes, Paris, L'Harmattan.

Eagen, Linda (1993), «Donde Dios todavía es mujer: Sor Juana y la teología feminista», en Sara Poot y Elena Herrera (eds.), $Y$ diversa de mí misma entre vuestras plumas ando. Homenaje Internacional a Sor Juana Inés de la Cruz, México, El colegio de México, pp. 327-340.

Fariña Busto, María Jesús y Beatriz Suárez Briones (1994), «La crítica literaria feminista, una apuesta por la modernidad», en J.M. Paz Gago, J.A. Fernández Roca y C. J. Gómez Blanco (eds.), Semiótica y modernidad. Actas del V Congreso internacional de la Asociación Española de Semiótica, vol. 1, A Coruña, Universidade da Coruña, Servizo de publicacións, pp. 321-331.

Ferreres, Rafael (ed.) (1993), La Diana enamorada de Gil Polo, Madrid, Espasa Calpe.

García Alvarez, Jesús (1997), El pensamiento filosófico de sor Juana Inés de la Cruz, Buenos Aires, Centro de Estudios filosóficos Tomás de Aquino.

Hutton, Joseph (ed.) (1967), Teresa de Cartagena. Arboleda de los enfermos y Admiración Operum Dey, Madrid, Anejos del boletín de la Real Academia Española.

Irigaray, Luce (1985), Speculum of the Other Woman, Nueva York, Cornell University Press.

Lewandowska, Julia (2012), «Sor Juana Inés de la Cruz y la crítica literaria feminista: controversias y contribuciones», Itinerarios, 15, pp. 43-66.

López Estrada, Francisco (ed.) (1970), Los siete libros de la Diana de Jorge de Montemayor, Madrid, Espasa Calpe.

López González, Aralia (1993), «Anticipaciones feministas en Sor Juana», en Sara Poot y Elena Urrutia (eds.), Y diversa de mí misma entre vuestras plumas ando. Homenaje Internacional a Sor Juana Inés de la Cruz, México, El Colegio de México, pp. 341-348.

Moi, Toril (2008), Sexual/Textual Politics, New York, Routledge.

Paz, Octavio (1982), Sor Juana Inés de la Cruz o las trampas de la fe, Barcelona, Seix Barral.

Ríos de la Llave, Rita (2010), “"Forget Your People and Your Father's House”: Teresa de Cartagena and the Converso Identitity», en Iwan-Michelangelo Džaprile et al. (eds.), Historicizing religion critical approaches to contemporary concerns, Pisa, Pisa University Press, pp. 41-54, <http://ehlee.humnet.unipi.it/books5/3/04.pdf>.

Rodríguez Magda, Rosa María (2005), «The pleasure of Simulacrum», en Elizabeth Sotelo (ed.), New Women of Spain, Münster, LIT Verlag.

Ruiloba, Rafael (1999), Sor Juana Inés de la Cruz: o la batalla entre el saber y el poder, Panamá, Editorial Portobello.

Sabat de Rivers, Georgina (1982), «Introducción», en Georgina Sabat de Rivers (ed.), Inundación castálida, Sor Juana Inés de la Cruz, Madrid, Castalia.

Salih, Sara (2002), Judith Butler, Londres/Nueva York, Routledge.

Teresa de Jesús (1982), Camino de perfección, ed. Efrén de la Madre de Dios y Otger Steggink, Madrid, BAC.

Teresa de Jesús (1984), La vida y Las moradas, ed. Rosa Navarro Durán, Barcelona, Planeta.

Trabulse, Elías (1974), Ciencia y religión en el siglo XVII, México, Colegio de México.

Valcárcel, Amelia (1994), Sexo y filosofía, Barcelona, Anthropos. 